\title{
Two Cases of Bilateral Paranasal Sinus Fungus Balls with Sphenoid Sinus Involvement
}

\author{
Woo Hyun Lee ${ }^{1}$, Yoon-Jong Ryu ${ }^{1}$, Jun Yeon Won ${ }^{1}$, and Junho Hwang ${ }^{2}$ \\ ${ }^{1}$ Department of Otolaryngology, Kangwon National University Hospital, School of Medicine, Kangwon National University, \\ Chuncheon; and ${ }^{2}$ Department of Otolaryngology, National Police Hospital, Seoul, Korea
}

\author{
접형동염을 유발한 양측성 진균구의 2예 \\ 이우현 ${ }^{1} \cdot$ 유윤종 ${ }^{1} \cdot$ 원준연 $^{1} \cdot$ 황준호 $^{2}$ \\ 강원대학교 의학전문대학원 강원대학교병원 이비인후과학교실 ${ }^{1}$, 국립경찰병원 이비인후과 ${ }^{2}$
}

\author{
Received December 10, 2018 \\ Revised January 16, 2019 \\ Accepted January 18, 2019 \\ Address for correspondence \\ Jun Yeon Won, MD, PhD \\ Department of Otolaryngology \\ Kangwon National \\ University Hospital, \\ 156 Baengnyeong-ro, \\ Chuncheon 24289, Korea \\ Tel +82-33-258-9109 \\ Fax +82-33-258-9486 \\ E-mail wonjy@kangwon.ac.kr
}

A fungus ball is the most common manifestation of fungal sinusitis. Bilateral involvement of fungus balls is rare, and bilateral sphenoid involvement is even more uncommon. The authors report two cases of bilateral fungus balls with sphenoid sinus involvement successfully treated with endoscopic sinus surgery. Both patients complained of nonspecific headache; diagnoses were made with CT and histopathological examinations, and surgical removal was achieved via transostial approach. Bilateral fungus balls involving the sphenoid sinus are rare but do occur; their removal is possible through endoscopic sinus surgery with a high cure rate. We thus recommend using CT scanning to identify typical findings of a sphenoid fungus ball even in bilateral paranasal sinusitis and perform aggressive surgical treatment. Korean J Otorhinolaryngol-Head Neck Surg 2019;62(10):598-601

Key Words Endoscopic Sinus Surgery $\cdot$ Fungi $\cdot$ Sinusitis $\cdot$ Sphenoid Sinus.

\section{서 론}

과거 진균성 부비동염은 비교적 드문 질환으로 알려져 있 었으나 최근 전산화단층촬영술(computed tomography, CT) 및 내시경 등 진단장비의 발달과 당뇨병의 증가, 장기이식 후 면역억제제의 투여, $\mathrm{AIDS}$ 와 같은 면역결핍질환의 증가, 광범 위 항생제의 잦은 사용 등의 요인으로 인하여 발생이 늘어나 는 추세이다. ${ }^{1)}$ 진균성 부비동염은 크게 침습적인 형태와 비 침습적인 형태로 구분되며 이중 진균구(fungus ball)는 비침 습적인 아형으로 면역기능의 이상 여부와 상관없이 진균 덩 어리가 부비동 공간 내에서 공의 형태로 뭉치며 주변 점막으 로의 침범 없이 자라는 것을 특징으로 하는 질환이다. ${ }^{2)}$ 대부 분의 진균구는 하나의 부비동에 국한되어 형성되며 $6.4 \%$ 정

This is an Open Access article distributed under the terms of the Creative Commons Attribution Non-Commercial License (https://creativecommons.org/licenses/by-nc/4.0) which permits unrestricted non-commercial use, distribution, and reproduction in any medium, provided the original work is properly cited.
도에서 복수의 부비동에 발생한다. ${ }^{3)}$ 하지만 복수에 발생한 경우도 해부학적으로 연속된 부비동에 발생하는 사례가 대 부분이며 양측 부비동에 동시에 발생하는 경우는 $1 \sim 3 \%$ 정 도로 드물다. ${ }^{4-6)}$ 또한 진균구가 흔히 발생하는 부비동은 상 악동이므로 접형동을 포함한 양측 부비동에 발생하는 증례 는 지극히 드물다.

최근 저자들은 접형동을 포함하여 양측 부비동에 동시에 발생한 진균구를 2 예 경험하였고, 이 환자들에게 내시경적 부비동 수술을 시행하여 성공적으로 치료하였기에 접형동을 병소로 하는 양측성 진균구에 관한 문헌고찰과 함께 보고하 는 바이다.

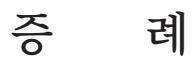

\section{증례 1}

63세 남자 환자가 8개월 전부터 지속되어 온 전두부위의 

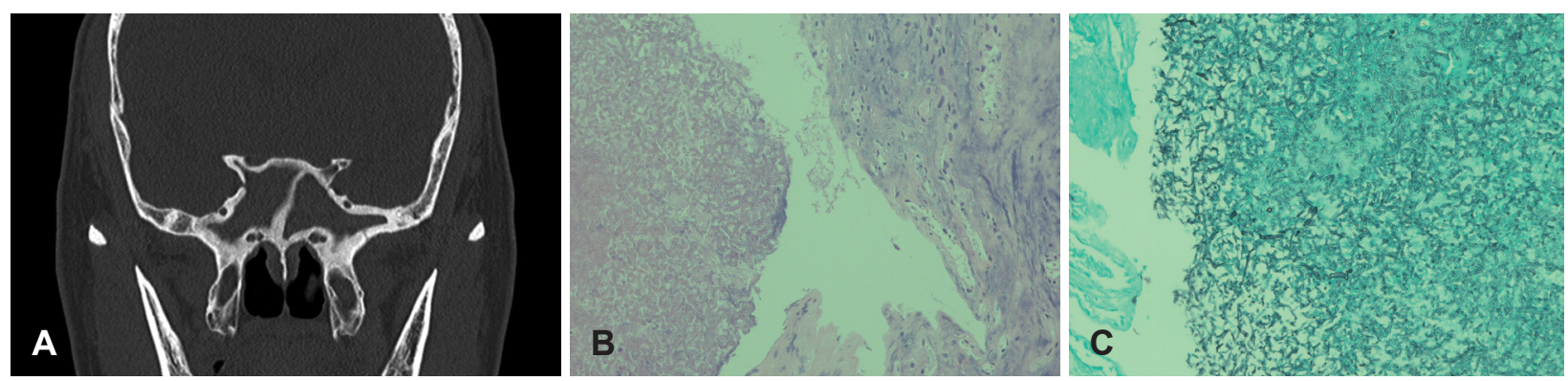

Fig. 1. Clinical findings of case 1. Coronal CT scan of paranasal sinus revealing bilateral sphenoid sinus opacification with adjacent bony sclerosis (A). Histopathology from the right sphenoid sinus revealing numerous fungal hyphae $(H \& E$ stain, $\times 200)(B)$. Histopathology from the left sphenoid sinus revealing acute angled dichotomous branching fungal hyphae (GMS stain, $\times 200)($ C).

통증과 최근 발생한 후비루를 주소로 내원하였다. 환자는 두 통으로 인하여 외부병원에서 약물을 지속적으로 복용하였 으며 2개월 전부터 후비루가 발생하여 본원 이비인후과로 내 원하게 되었다. 과거력상 40년 전 폐결핵을 않았으나 약물 복 용으로 완치판정을 받았으며 이외에 특이한 병력은 없었다. 비강내시경을 활용한 이학적 검사에서 양측 접형사골함요 (sphenoethmoidal recess)로부터 시작하여 후비공으로 배출 되는 점액농성의 비루가 관찰되었으며 이외에 비중격의 만곡 이나 비용종 등의 소견은 관찰되지 않았다. 부비동 전산화단 층촬영(ostiomeatal unit $\mathrm{CT}, \mathrm{OMU} \mathrm{CT}$ ) 검사에서 양측 접 형동을 가득 채우고 있는 혼탁음영과 접형골의 심한 경화가 관찰되었으나 명백한 석회화의 소견은 관찰되지 않았다(Fig. 1A). 환자에게 4주간 항생제(amoxicillin $500 \mathrm{mg} /$ clavula- $^{-}$ nate potassium $125 \mathrm{mg}$ 1일 3회 2주, clarithromycin $250 \mathrm{mg}$ 1 일 2회 2주)를 투여하였으나 증상의 호전은 없었고, 이에 접 형동의 병소의 진단 및 제거를 위해 내시경적 부비동 수술을 시행하기로 하였다. 경접형공 접근(transostial approach)을 통해 우측 및 좌측 접형동절개술(sphenoidotomy)을 시행하 였고 양측 접형동 내부에서 모두 점액농성 비루와 함께 흑갈 색의 덩어리가 관찰되었다. 이에 진균구로 판단하였고 잔존 물을 남기지 않기 위하여 접형동 입구부를 크게 열어준 후 흡입기와 식염수 세척을 통하여 덩어리를 완전히 제거하였 다. 제거 후 관찰한 접형동 내부의 점막은 심한 폴립양( $\mathrm{pol}-$ ypoid)의 부종이 관찰되었으나 주변 골의 손상이나 접형동 격막의 결손은 관찰되지 않았고 이에 수술을 종료하였다. 수 술 중 채취한 흑갈색 덩어리의 조직검사 상 양측 모두 아스 페길루스균(Aspegillus fumigatus)이 관찰되었다(Fig. 1B, C). 수술 후 환자의 전두부 통증 및 후비루는 호전되었으며 10 개월이 경과할 때까지 증상의 재발 없이 경과 관찰 중이다.

\section{증례 2}

86세 남자 환자가 5년 전부터 지속되어온 가래와 후두부 위의 통증을 주소로 내원하였다. 본과 방문 이전 호흡기 내
과에서 진료를 받았으며, 이때 촬영한 X-ray 상 우측 상악동 염이 의심되어 이비인후과로 의뢰되었다. 과거력상 고혈압으 로 약물복용 중이며 신장결석으로 50년 전 수술을 받은 경력 이 있었다. 30 갑년의 흡연력이 있었으나 30 년 전부터 금연을 하여 유지하여 온 상태이며 일주에 3회가량 소주 반병 가량 의 음주력도 있었다. 비내시경을 활용한 이학적 검사상 비중 격의 우측 만곡 이외에는 특별한 이상 소견이 관찰되지 않았 다. $\mathrm{OMU} \mathrm{CT}$ 검사상 우측 상악동과 좌측 접형동에 혼탁음 영이 관찰되었으며 우측 상악동에는 석회화의 소견이 보였고 좌측 접형동은 부분적인 혼탁 소견만이 관찰되었다(Fig. 2). 이에 병소들을 제거하기 위해 내시경적 부비동 수술을 시행 하였다. 전신마취 후 내시경 시야 하에 우측 상악동 절개술 을 시행하였고 내부에 흑갈색의 덩어리를 관찰하였으며 이를 거즈를 이용한 제거술(gauze-assisted technique)을 활용하 여 흡인기와 생리식염수 세척을 통해 완전히 제거하였다. 좌 측 접형동 병소의 제거를 위하여 경접형공 접근을 통해 접형 동 절개술을 시행하였고 접형동 내부에 갈색의 덩어리를 관 찰하여 흡인기와 세척을 통하여 제거하였다(Fig. $3 \mathrm{~A}$ ). 양측 에서 채취한 덩어리를 조직검사 하였으며, 양측 모두에서 아 스페길루스균이 관찰되어 양측성 진균구로 확진하였다. 수술 후 환자의 가래와 두통은 호전되었으며 9개월이 경과한 현재 까지 특별한 재발의 증거 없이 관찰 중이다(Fig. $3 \mathrm{~B}$ ).

\section{고 찰}

진균구는 진균성 부비동염의 가장 흔한 형태이며 발생 기 전이 명확하게 알려져 있지는 않으나, 부비동의 자연공으로 침투한 진균이 염증반응을 유발하고 부비동의 자연공을 막 아 내부의 산소분압을 떨어뜨려 저산소환경을 조성하고 진 균의 성장에 적합한 환경을 제공하여 진균의 증식을 유도함 으로써 형성된다는 가설이 널리 알려져 있다.)

진균구는 상악동에서 가장 호발하는 것으로 알려져 있으 며 그다음으로 접형동에서 호발한다. ${ }^{8)}$ 연구에 따라 그 발생 
빈도의 차이는 있지만 접형동에서 진균구의 발생은 전체 진 균구 발생의 8 24.7\%가량으로 보고되어 있다. ${ }^{2,9-12)}$ 또한 진 균구는 국소적인 원인에 의해 발생하는 것으로 추정되는 질 환이기 때문에 양측성으로 발생하는 경우는 1 3\%가량으로 드물다. ${ }^{4-6)}$ 위의 사실을 종합하여 볼 때 본 증례와 같이 접형 동을 포함한 양측성 진균구의 발생은 극히 드물다는 것을 알 수 있다.

109명의 진균구 환자를 대상으로 한 Klossek 등 ${ }^{3)}$ 의 연구
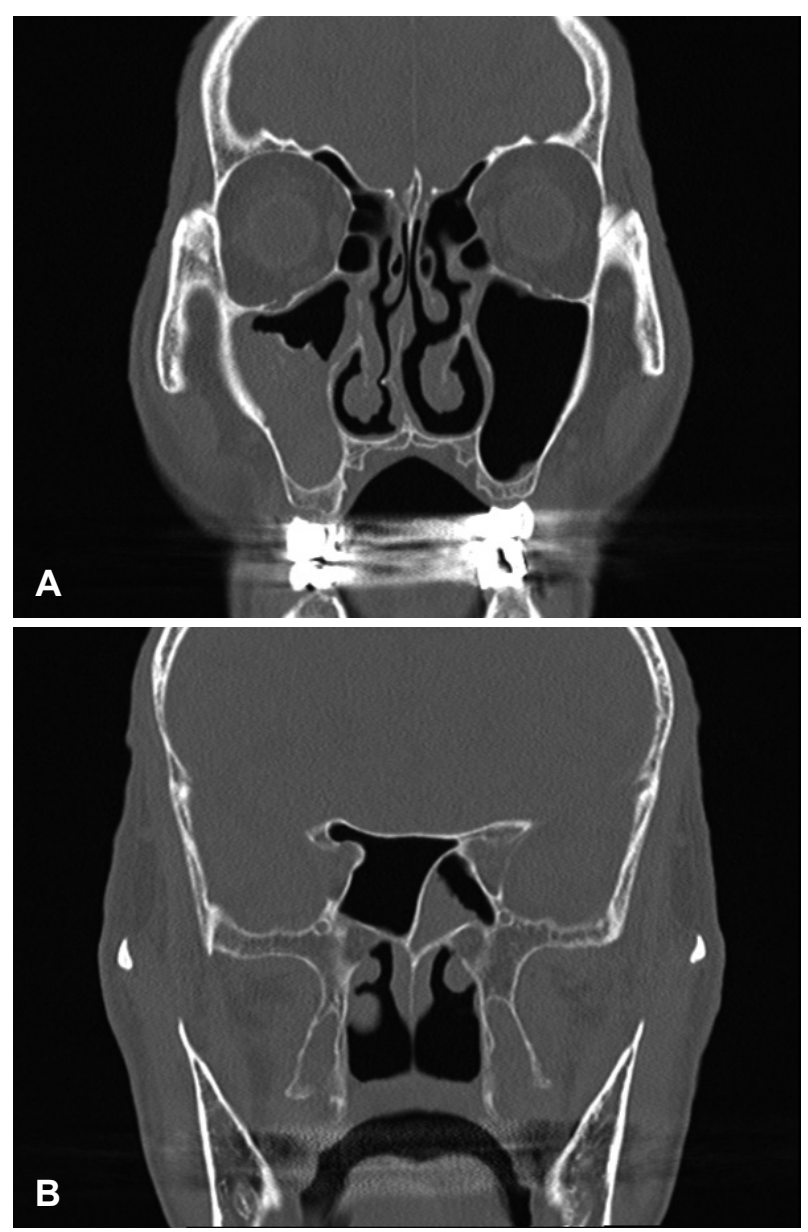

Fig. 2. CT scan revealing calcified opacification in the right maxillary sinus $(A)$ and partial opacification in the left sphenoid sinus (B).
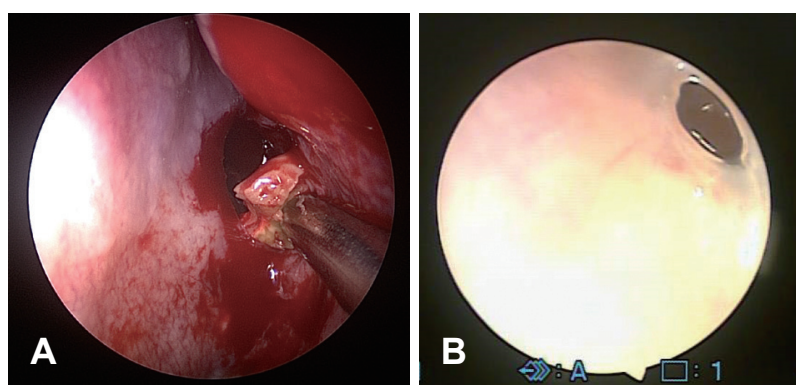

Fig. 3. Fugus ball in left sphenoid sinus (intra-operative endoscopic view) (A) and post-operative 9 month endoscopic finding of wellhealed left sphenoid sinus $(B)$.
에서 양측성 진균구는 2예에서 관찰되었으나 모두 상악동에 발생하였으며, Lee 등이이 보고한 8예의 양측성 진균구 환자 중 양측 접형동을 침범한 것은 1 예이고 일측 접형동과 반대 측 상악동을 침범한 경우가 2예였다. 또한 7예의 양측성 진 균구를 보고한 Shim등 ${ }^{13)}$ 의 연구에서는 접형동을 침범한 예 는 전혀 없었다. 118 명의 진균구 환자를 대상으로 시행한 다 른 연구에서는 28 명의 환자에서 접형동의 진균구가 발생하 였고 이 중 2 명의 환자만이 양측성으로 보고되었으나 이 중 1 예의 경우는 접형동 격막의 결손이 관찰되어 이 연구의 증 례 1과 같이 격막이 온전한 상태에서 양쪽 접형동을 모두 침 범한 경우는 1 예 만이 보고되었다. ${ }^{14)}$ 최근에 발표된 20 년간 538 명의 진균구 환자를 대상으로 한 대규모 연구에서는 17 명(3.2\%)의 환자만이 양측성이었고 이중 양측 상악동을 침 범한 경우가 가장 흔한 유형으로 조사되었다. ${ }^{15)}$

접형동에 진균구가 존재할 경우 환자의 가장 흔한 증상은 두통이며 이어 후비루, 시력저하, 착후각의 순으로 알려져 있 다. ${ }^{14)}$ 두통의 양상은 이환된 부비동부위에 국한되지 않고 전 두부, 안구후부, 후두부 등 다양한 양상의 통증으로 발현되 므로 특별한 신경학적 이상 없이 두통이 동반될 때는 접형동 진균구의 가능성을 염두 하여 이에 대한 검사를 시행해야 한다. ${ }^{16)}$ 본 연구의 두 증례의 경우도 환자가 공통적으로 접형 동 진균구의 가장 흔한 증상인 두통과 후비루를 호소하고 있었고 두통의 양상은 증례 1 의 경우 전두부위의 통증을, 증 례 2의 경우 후두부위의 통증을 호소하였고 신경과 등 타과 의 진료에서 특별한 신경학적 이상 소견은 발견되지 않았다.

CT 검사는 진균구 진단에 가장 중요한 검사이며 33 64\% 의 병변에서 석회화가 관찰되는 것으로 알려져 있다. ${ }^{17)}$ 본 증 례에서는 증례 2의 상악동에서만 석회화가 관찰되었고 나머 지 접형동 병변들의 경우는 석회화가 관찰되지 않았으므로 석회화 병변을 진균구의 절대적인 진단의 기준으로 삼기는 어렵다. 접형동의 진균구를 진단할 수 있는 추가적인 CT 소 견으로는 주변 골조직의 비후나 경화를 들 수 있으며 본 증 례 1에서 명확한 주변 골의 경화를 확인할 수 있었다. ${ }^{18)} \mathrm{CT}$ 상 진균구에 관한 명확한 증거가 없거나, 뇌, 안구 등의 합병증 이 의심되는 경우, 종양 등 다른 병변과의 감별이 필요한 경 우에는 자기공명영상(magnetic resonance imaging)이 도움 을 줄 수 있으며 진균구의 전형적인 소견은 $\mathrm{T} 1$ 강조영상에서 낮은 신호강도를 보이고 $\mathrm{T} 2$ 강조영상에서 더 감소한 신호강 도를 보인다. ${ }^{2)}$ 본 증례의 경우 증례 1 에서는 주변골의 경화, 증례 2에서는 상악동의 석회화 등을 통해 진균구를 의심할 수 있었기 때문에 추가적으로 자기공명영상 검사를 시행하 지는 않았다.

접형동 진균구에 대한 치료는 수술적인 제거이며 수술의 
목적은 진균구 덩어리를 완전히 제거하고 접형동의 적절한 환기 및 배출을 유지하는 것이다. ${ }^{14)}$ 내시경을 이용하여 경접 형공 접근법이나 경사골동(transethmoidal) 접근법으로 접 형동에 대한 접근이 가능하므로 술자의 선호에 따라 적용할 수 있으며, 본 연구의 두 증례 모두 경접형공 접근을 활용하 여 진균구 덩어리의 완전한 제거 및 접형동의 환기 개선이 가능하여 성공적인 치료 결과를 보였다.

수술 후 재발이나 잔여 진균구 존재의 가능성은 접형동 $(0 \sim 3.6 \%)$ 이 상악동 $(0 \sim 22.5 \%)$ 에 비해 낮다. ${ }^{2,5,19,20)}$ 이는 접형 동의 진균구가 상악동에 비해 전장에 걸친 접근이 용이하여 완벽한 제거가 가능하며 진균구 발생의 한 원인으로 추정되 는 아연과 철분 성분을 포함한 치과재료의 노출이 상악동에 서는 가능한 반면 접형동은 이러한 위험요인이 없기 때문으 로 생각된다.

접형동을 포함한 양측성 진균구는 매우 드물기는 하지만 발생 가능하고 수술을 통하여 확진 및 완전한 치료가 가능 하며 높은 완치율을 보이는 질환이다. 따라서 두통, 후비루 등을 호소하는 환자에서 CT 등의 검사를 시행하여 진균구 를 시사하는 영상학적 소견과 접형동을 포함한 양측 부비동 염을 보이는 경우, 양측성 진균구의 가능성을 염두에 두고 진단 및 치료의 목적으로 적극적인 내시경적 부비동 수술을 시행할 것을 권유한다.

\section{ORCID}

Jun Yeon Won

https://orcid.org/0000-0002-1615-3760

\section{REFERENCES}

1) Stammberger H. Endoscopic surgery for mycotic and chronic recurring sinusitis. Ann Otol Rhinol Laryngol Suppl 1985;119:1-11.

2) Nicolai P, Lombardi D, Tomenzoli D, Villaret AB, Piccioni M, Mensi M, et al. Fungus ball of the paranasal sinuses: Experience in 160 patients treated with endoscopic surgery. Laryngoscope 2009; 119(11):2275-9.

3) Klossek JM, Serrano E, Péloquin L, Percodani J, Fontanel JP, Pessey JJ. Functional endoscopic sinus surgery and 109 mycetomas of paranasal sinuses. Laryngoscope 1997;107(1):112-7.

4) DeShazo RD, O’Brien M, Chapin K, Soto-Aguilar M, Swain R,
Lyons M, et al. Criteria for the diagnosis of sinus mycetoma. J Allergy Clin Immunol 1997;99(4):475-85.

5) Ferreiro JA, Carlson BA, Cody DT 3rd. Paranasal sinus fungus balls. Head Neck 1997;19(6):481-6.

6) Lee DH, Joo YE, Lim SC. Fungus balls of the bilateral paranasal sinuses. Indian J Otolaryngol Head Neck Surg 2013;65(Suppl 2):320-3.

7) Cho IK, Chung YJ. A case of multiple discrete fungus balls of the bilateral paranasal sinuses. Korean J Otorhinolaryngol-Head Neck Surg 2009;52(5):457-60.

8) Ferguson BJ. Fungus balls of the paranasal sinuses. Otolaryngol Clin North Am 2000;33(2):389-98.

9) Dufour X, Kauffmann-Lacroix C, Ferrie JC, Goujon JM, Rodier MH, Karkas A, et al. Paranasal sinus fungus ball and surgery: A review of 175 cases. Rhinology 2005;43(1):34-9.

10) Pagella F, Matti E, De Bernardi F, Semino L, Cavanna C, Marone $\mathrm{P}$, et al. Paranasal sinus fungus ball: Diagnosis and management. Mycoses 2007;50(6):451-6.

11) Kim TH, Na KJ, Seok JH, Heo SJ, Park JH, Kim JS. A retrospective analysis of 29 isolated sphenoid fungus ball cases from a medical centre in Korea (1999-2012). Rhinology 2013;51(3):280-6.

12) Seo YJ, Kim J, Kim K, Lee JG, Kim CH, Yoon JH. Radiologic characteristics of sinonasal fungus ball: An analysis of 119 cases. Acta Radiol 2011;52(7):790-5.

13) Shim BS, Song YJ, Han KY, Kim JH, Ha MS, Kim JY. Clinical features of bilateral paranasal sinus fungus ball. J Rhinol 2010; 17(1):33-6.

14) Karkas A, Rtail R, Reyt E, Timi N, Righini CA. Sphenoid sinus fungus ball. Eur Arch Otorhinolaryngol 2013;270(3):893-8.

15) Yoon YH, Xu J, Park SK, Heo JH, Kim YM, Rha KS. A retrospective analysis of 538 sinonasal fungus ball cases treated at a single tertiary medical center in Korea (1996-2015). Int Forum Allergy Rhinol 2017;7(11):1070-5.

16) Lim HS, Yoon YH, Xu J, Kim YM, Rha KS. Isolated sphenoid sinus fungus ball: A retrospective study conducted at a tertiary care referral center in Korea. Eur Arch Otorhinolaryngol 2017;274 (6):2453-9.

17) Kim SW, Park YJ, Kim SW, Kang MG, Joo YH, Cho JH. A clinical analysis of fungal sinusitis. Korean J Otolaryngol-Head Neck Surg 2005;48(3):332-7.

18) Leroux E, Valade D, Guichard JP, Herman P. Sphenoid fungus balls: Clinical presentation and long-term follow-up in 24 patients. Cephalalgia 2009;29(11):1218-23.

19) Castelnuovo P, Pagella F, Semino L, De Bernardi F, Delù G. Endoscopic treatment of the isolated sphenoid sinus lesions.Eur Arch Otorhinolaryngol 2005;262(2):142-7.

20) Socher JA, Cassano M, Filheiro CA, Cassano P, Felippu A. Diagnosis and treatment of isolated sphenoid sinus disease: A review of 109 cases. Acta Otolaryngol 2008;128(9):1004-10. 